\title{
Miliary Tuberculosis
}

National Cancer Institute

\section{Source}

National Cancer Institute. Miliary Tuberculosis. NCI Thesaurus. Code C35086.

I would say the hematogenous widespread dissemination of tuberculosis in the body.

The term derives from the chest $\mathrm{X}$-ray image of the tiny $(1-5 \mathrm{~mm})$ tuberculosis lesions which are seen through out the lung parenchyma. 